\title{
Cognitive Stylistic Conceptualization of Legal Translation
}

\author{
Dr. Hasan Said Ghazala \\ Professor of Translation and Stylistics, Department of English, College of Social Sciences, Umm \\ Al-Qura University, Saudi Arabia \\ Email: hsghazala@uqu.edu.sa
}

\begin{abstract}
:
Among the newly developed ideas in the relationship of translation to style is the strong link between translation and cognitive stylistics. The result of this link is the introduction of cognitive conceptualization to translation as one way of comprehending and rendering meaning of the SL into the TL. On the other hand, it can help solve some problems of legal translation based on cognitive cultural conceptualization of legal terms and expressions.

This paper is an attempt to introduce new clues for sorting out a number of legal terminology in the light of latest cognitive approaches to the conceptualization of style which can be applied to legal language in the translation between the two languages, Arabic and English. This is achieved through introducing cognitive stylistic approaches to the conceptualization of the style of legal language in translation and how untrodden ways of legal meanings and implications can be traced and unearthed in the process. The paper ends up with some conclusions about suggesting way-out solutions to several problems of legal translation between the two languages concerned, to be put in use later by legal translators.
\end{abstract}

Keywords: Cognitive, Conceptualization, Style, Stylistic, Legal translation, Legal language. 


\section{Introduction: Conceptualization of Style as Choice}

Style is nowadays defined in terms of a linguistic choice in the first place. A linguistic choice is made by the writer on the basis of options available in language. These options are in other words potential cognitive conceptualizations available to writers in general. Hence, style is the total options available in the syntactic, semantic, phonological and pragmatic systems of language in particular. In this sense, expression and content "can be viewed as a matter of choice"( Leech and Short (1981: 29). They point out that a myriad of stylistic possibilities (e.g. choices of potential conceptualizations) are available in language, and differing choices in one clause can indicate varying 'conceptualisations' of the same event (p. 191). As also declared by Traugott and Pratt (1980: 34), the more we understand the stylistic choices available in the language system, the more we appreciate the infinite possible variety and combinations of these choices. They introduce the pioneering idea that links the concept of style as choice to 'mind style' and, hence, to meaning. They argue that mind style is appropriate where consistent stylistic choices are made through a text.

In Carter's view, style "results from a simultaneous convergence of effects at a number of levels of language organization" (in D’haen (ed.), 1986). Further, An interesting differentiation between language and style in terms of choice is made by Traugott and Pratt (1981: 29). Language is the sum total of the structures available to users, whereas style concerns the characteristic choices in a given context. Thus, style consists of "choices made from the repertoire of language" (Leech and Short, 1981: 38). It is a type of domain in the sense of the certain choices made by a particular writer, in a particular genre, in a particular text. Style, then, may be defined in terms of the variant linguistic choices made in the text by the individual author, which are in effect stylistic choices made in preference to others potentially available in a language system. In theory, every stylistic/linguistic choice is in some way functional (i.e. cognitively conceptualized).

A new trend of stylistics, cognitive stylistics, has emerged in the past fifteen years. Boase-Beier, maintains that cognitive stylistics "...explores the notion of style-as-mind...” (2006: 75). Mind style has been seen by Fowler as "any distinctive linguistic representation of an individual mental self". The term was originally introduced by Fowler, who defines it precisely as "cumulatively consistent structural options, agreeing in cutting the presented world to one pattern or another, give rise to an impression of a world-view, what I shall call a 'mind style"” (1977: 145). 
Boase-Beier has not gone too far from this notion of mind style by distinguishing it "as a textual feature from the corresponding cognitive state which can be attributed to it ..." (ibid.: p. 76). Simply put, style as mind is a way of conceptualizing language and style in the sense that our choices represent certain concepts of ours in a certain text and context. Consequently, any stylistic /linguistic choice is an expression of concept -be it overt or covert- that has to be considered in our comprehension of its meaning.

Thus, conceptualization is seen as the body of formally represented knowledge of objects, concepts and other entities that are assumed to exist in some area of interest and the relationships that hold among them" (see Genesereth and Nilsson 1987; Madsen and Thomsen 2009; Gómez GonálezJover especially 2006: 219. In Boase-Beier, 2006). No text has ever been written or survived in vacuum, or directed to anything else but mankind. This means readers have their rights to read and interpret the text in their own terms of mind, culture, social and religious conventions, ideology, personal experience and background common knowledge of the world. They have a sufficient amount of freedom to understand and construct the writer's stylistic choices in that large context of theirs, keeping an eye on the author's choices and assumed intentions, however indirectly. As Fowler argues, style is not just a question of different ways of saying or expressing the same thing (in Boase-Beier, 2006: 53). Stylistic choices “reflect a speaker's (subjective) choice of a given conceptualization", and are a reflection of different content rather than different expression (see also Leech and Short, 1981). Because stylistic choice is optional to speakers, or writers, it is telling about the person who uses this very particular choice. A choice is made from those structures that mind universally makes available for language users. Such a view of style as mind is a cognitive approach of conceptualising stylistic choices that has left the door wide open for different readings and different interpretations of the speaker's choices - or concepts - by different readers in different cultural and ideological settings.

As to the translator, he/she is after all a reader, a careful and informed reader, who also has his/her own style and stylistic choices, mind, socio-cultural background, ideology, experience and knowledge of the world. More recently, Semino talks of "the social environment of translation" (2007) (see also Tyulenev (2014) on the strong ties between translation and sociology). A pragmatic view of a translator is he/she is a reader and a communicator. He/she reads the source text with the aim of constructing what he/she perceives as the text's meaning - rather than reconstruct the author's meaning - to construct it this time in the target text. 
By constructing the source text's meaning in the target language, the translator has an ambitious aim of producing the same potential effects on the target text readers that reflect those produced on the source text readers, though with variations (see also Ghazala, 2011 and 2018 for further discussion).

Conventionally speaking, within translation studies, the process of translation has been described in terms of gain, loss, and betrayal, thus, minimising translation to a mere reproduction, or reflection of an effect, an intention, or a message. Now the process of translation itself has been receiving the greater amount of focus in cognitive studies of translation. It is a process of interaction in a new context, a new reading, a new writing from a cognitive/mental perspective of style. Translation to many contemporary translation theorists (see Semino, 2007.) is a form of writing and perhaps new conceptualization of the original through its stylistic aspects.

\section{Cognitive Conceptualization of Legal Style}

Regarding translating the cognitive style of conceptualization of legal language, the following points can be put forward to consider:

(1) Conceptualization involves the extension of legal concepts in both languages, English and Arabic. That is, the concept of 'crime' (جريمـة) breeds other related concepts including:

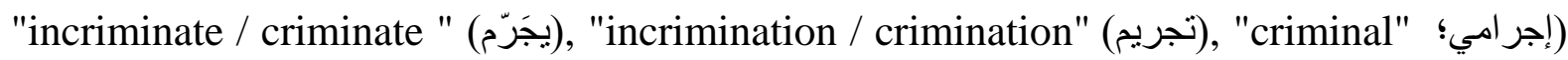
(المجرم), "criminal act" (عمل/سـلوك إجرامي), criminal motive (غاية إجر امية), "criminal charge"

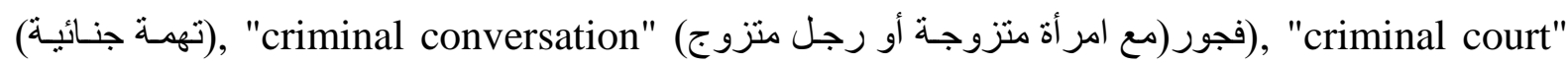
(محكمة جنائية); "criminology" (تلم الجر ائم؛ العلم الجنائي), "criminal libel" (تشهير جنائي), "criminal

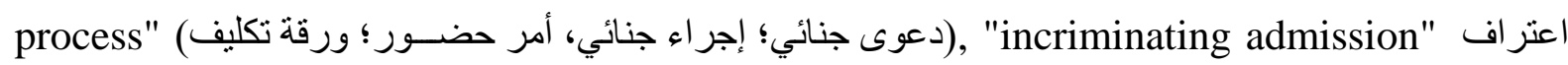
مجرَّم/تجريمي), etc. every one of these terms is a concept of its own that is conceptualized from the original concept of "crime".

This series of conceptualization is still going own to generate new concepts related to the root. For example, "criminal libel" (تشهير جنائي) is a new conceptualization that is related to the publication of a defamatory matter as by printed statement or a picture usually in the newspaper or other mass media. On the other hand, each of these concepts are supposed to be taken by readers and translators on its own as a conceptualization that is independent of "crime" for it is different from it. A case in point is "criminal conversation" فجور(مع امر أة) متزوجة أو رجل منزوج) it has nothing to do with the literal meaning of "conversation" 
(حديث/محادثة/كلام), but it is a conceptualization f a different type of crime, as also stated by Bajcic who rightly notes that "the process of conceptualizing one and the same legal term in different legal fields does not always proceed smoothly"(2011).

(2) The principle of proportionality is one of the basic features of concepts (see Bajicic, 2011). This very principle allows for generating newborn concepts that represent new dimensions of conceptualizing words. It is based on the fact that "nothing is absolute, everything is relative, except God." Hence, new derivations are produced from each word. This calls for relativity principle of language and thought proposed by Whorf (1956) and Sapir (1949). It partly consists of (i) Linguistic Determinism; and (ii) Linguistic Relativity. According to linguistic determinism, language determines thought. However, linguistic relativity states that language encodes different distinctions (see Jakobson, 1960; Crystal, 1987; Malmkjær, 2005; and Boase-Beier, 2006 for further details). Sapir and Whorf maintain that each language involves two interplaying types of aspects: the particular, cultural-specific aspects as a unique way of viewing the world, and the universal aspects which languages may share. (See Ghazala, 2011: 137-9 for further details). Hence, the concept of relativity of translation encapsulates the relative nature of the meaning transported into the target text, as opposed to one absolute, perfect and invariable meaning of the source text. In contemporary cognitive studies of style, and as indicated above, meaning is constructed mainly on the basis of the conceptualisation of stylistic choices of the source text and their effects and implications. This cognitive enterprise draws heavily on the views of some translation theorists like Hyde, Lecercle, Venuti, who accept that different languages embody different kinds of thinking. This is not a barrier to translation if pragmatic and contextual factors are taken into account (which is what cognitive approaches to language and translation do). More so, one thinks in a different way in every language, for one adopts the particular mindset of that language (see Nord (1997), Gutt (2000) and Boase-Beier (2004a, 2004b and 2006).

In legal translation the concept of proportionality (or relativity) is useful at translating between two languages as many SL concepts may be conceptualized in a relative (or approximate) way (see Ghazala, 2020 and Ghazala 2022 (forthcoming) on the proximity principle of legal translation). 
The word "crime", exemplified above, is supposedly an absolute concept that is generally conceptualized in Arabic into the absolute straightforward equivalent (جريمة). Now, is the concept applicable identically to all types of crime in both languages? The answer is definite NO, for not all crimes in English are crime in Arabic, and vice versa. Killing, stealing, assaults of all types, cheating, corruption, money laundering and so on are all crimes in the law of both languages and cultures. However, adultery is a crime in Arabic law, not in English law. By the same token, getting married to more than one woman at the same time is a crime in English (called "polygamy"), whereas in Islamic law, it is legal. On the other hand, the concept itself, "crime" (جـريـمــة) is proportional in volume, degree, resonance and punishment. For example, if one is rich and does not help one's poor parents and relations, one is described as committing a moral crime in an Arab Community and has a negative social resonance, but not in an English community. On the other hand, refusing to help one's poor relatives is less in volume than assaulting them, etc. All these considerations of proportionality of concepts should be taken into account by legal translators between English and Arabic.

(3) Law is composed of words or labels, but these are different from the concepts that are the building blocks of law. A single label can refer to multiple concepts, or multi-meanings of polysemy. In other words, words that have more than one meaning have different ways of conceptualization. For example, "right" (يمين) means one thing when giving directions; another thing (صحح) opposing to wrong; yet quite another (حق) when discussing the legal system. Even within the law, the concept of a right is different when thinking about an individual's freedom from torture than when talking about Mother Nature's right to remediation (see also Cao, 2010, and Alcaraz et al, 2002).

(4) Each legal concept might have subconcepts (مفاهيم فرعية). "Murder", for example, is killing with (1)malice (الحقد), (2) aforethought or intent (النيـة المبيتـة); (3) motive(s) (الدافع/الدو افع)) behind killing and (4) device (أداة) for killing. This means that law is composed of concepts and subconcepts, structured together in particular ways.

(5) Legal concepts should be resonant in the sense that they must be collocable in a way that they are distinct from the ordinary meaning attached to the same terms. Each label (i.e. word) goes with the appropriate word, or, the right word with the right word. This is a direct reference to legal collocations. 
A case in point is "Cross-examination" which can be translated into تحقيق تقاصّ؛ التحقيق مع) (الثهود؛ مساءلة الثهود؛ توجيه أسئلة للشهود؛ مناقثة الثهود؛ استجو اب الثهود) Only the last one (followed by the penultimate version 5) can be usually used to translate the original concept appropriately in legal context for the other translations involve different dimensions of conceptualization, as shown below:

(1) تحقيق تقاصن :cross-investigation in general

(2) التحقيق مع الثهود: investigation with the witness

(3) مساءلة الثهود: calling the witness to account/impeachment

(4) توجيه أسئلة للثهود :asking questions to the witness

(5) مناقشة الثهود: discussing the witness

(6) استجواب الثهود : questioning the witness

The first is vague, uncommon, unknown and not limited to legal language. The second suggests a kind of intelligence/police investigation, which is not applicable to the SL meaning. The third, on the other hand, implies bringing some accusation to the witness which is an irrelevant concept in this context. The fourth represents a subconcept, or a semiconcept of the original for the cross-examination does not involve asking the questions he/she has to answer, but also it involves reactions and maybe questions asked by the witness. However, number 5 is the closest to the SL concept ad meaning for the witness is supposedly engaged in a kind of quiet dialogue or discussion. As to the last one, it means that the witness is being questioned certain questions to answer freely with no pressure from anyone and has the right to answer a question or not, and also has the right to enquire about something. Above all, this is the most common, natural and appropriate collocation that has a special resonance, used frequently and intuitively by men of law and laymen alike. Indeed, it is one of the popular phrases in the daily sessions of courts among other related phrases like: ناد على الثـاهد / الثـهود لاستجو ابهم؛ يمكن لمحامي الدفاع استجو اب الثاهد/ الثهود؛ تمانم (بعد اسـتجو اب الثــهود.../. Thus, the whole collocation is a special conceptualization ensuing particular subconcepts or presuppositions associated with it.

Corruption is also unquestionably a resonant and fecund concept, in that it is intuitively undesirable to most observers and conveys a rich array of negative meanings. 
This rich array is a part of the problem because corruption can mean many different things and many different types of legal crimes. So the term has been-defined in many different ways e.g. bribery, cheating, blackmail, embezzlement, money laundering, smuggling, theft, fraud, graft, extortion, abuse of discretion, favouritism/ nepotism, clientelism (i.e. client politics), networking, dishonesty, criminal offence of some kind, etc.) .

(6) The domain of legal concepts is the legal system; it is not meant to encompass anything outside it. Common-law marriage(الزواج الثــرعي/القانوني/حسـب القانون) refers to the idea that the marriage is legal, even if not formally recorded (as is the case with many marriages in the Arab and Muslim countries). Consistency requires that a concept carry the same meaning in different empirical contexts.

(7) Some legal concepts can be limited to very narrow conceptualizations of technical applications. For example, in thinking about different types of political "regimes", one might distinguish authoritarian regimes from democracies, or might alternately look at particular subtypes within each category: electoral authoritarians, totalitarians, military regimes, junta, dictators and absolute monarchies, or presidential and parliamentary democracies.

(8) Sometimes concepts are defined by their neighbouring concepts as is the case with legal collocations, where each couple or triple of words form a mini-context that delineates a legal concept and its meaning. For example "pass" has several meanings, but when it collocates with "law" it produces a new legal concept related to setting a new law officially (يسن قانوناً), etc.

(9) There are underlying conceptualized interrelationships among different concepts. One example is the relationship between democracy and other concepts:

(1) Does democracy increase economic growth?

(2) Does race correlate with voting behaviour?

(3) Do people behave rationally in their investment decisions?

(4) Are military alliances stable across time?

These are examples of another possible extension of conceptualization of a concept to subsume different domains and fields of knowledge which have some relevance to the same concept however indirectly. 
In translation, all these concepts, subconcepts and new conceptualizations should be taken care of by legal translators due to the importance of differentiating between various conceptualizations that are variably different from time to time and from one language to another. Hence the significance of the style of conceptualization in legal translation.

\section{Conceptual vs. Functional Approach to legal Translation}

Nida (1964, 1969 and 1982, 2001) puts forward a theory of functional equivalence which has a great influence on translation, including legal translation. The term 'functional equivalence' highlights the impact the message has on the target language and the source language reader. In this regard, Šarčević (2000: 238) divides functional equivalence into three groups: nearequivalence, partial equivalence, and nonequivalence. The method the legal translator chooses depends on the degree of equivalence within the concept, while near equivalence may require the translator to find a phrase in the target language with the same meaning (2000: 238, in ibid: 204).

Based on Stolze (2013 \& 2011:105-127), Piecychna (2013) adopts the functional equivalence method in legal translation. Functional equivalence means the interrelations and the communicative values between the (SL) and the (TL) words, sentences and terminology (Nord 1997:138). "The translator uses the functional equivalence when translating legal terms from one legal system in a given language and the other legal system of the target language", (see Cao 2007:32, and 2010 for further details). If there is a language that uses multiple legal systems such as Arabic Language, the translation between two different legal systems using the functional equivalence is a must. One practical example is "Magistrate" which holds different connotations within the same language, as it may mean (Judge), (Key Law Maker) and (Man of Authority). Yet, are these meanings the exact functional equivalence with respect to the legal system concerned? The translator needs to dig deep in the (SL) legal system terminology in order to extract the exact resemblance of the meaning and functional equivalence of the legal term in order to be accurate in translation. The Arab Translator might convey a different meaning of "Magistrate" which is (the investigation judge (قاضي التحقيق / المحقق) or (the investigation principal), which is an inaccurate translation and not the functional equivalence. Yet, in Saudi Legal system, the word "Magistrate" does not exist as far as the functional equivalent technique is concerned for there is no such equivalence embedded in the legal system of the country. 
Instead, there is a committee that plays the role of a judge or magistrate instead of one legal authoritative individual. Thus, the legal translator should constantly trace the functional equivalent among languages as much as their different legal systems.

As to conceptualization of legal translation and its relevance to the functional equivalence, it seems to me that the search for the functional/cultural equivalence is not dissimilar to, and does not contravene at heart with the cognitive conceptualization of the meanings of legal terms especially those described as unfindable, or culturally, religiously, politically or socially different. That is, the functional/cultural equivalence is in other words a TL-oriented translation of an SL legal term, and cognitive conceptualization is a reference to rendering meaning in accordance to the TL values, culture and mindset. Hence the closeness of functional and cognitive approaches to legal translation.

\section{Translating Legal Cognitive Conceptualization:}

\section{Problems and Solutions}

Following are sample examples of some problems of translating legal conceptualization in application, followed by their suggested solutions:

Problem 1: Legal translators might find it difficult to understand the concept and process of conceptualization of words in the first place, and whether it is universal or local / cultural in the sense that both the SL and the TL have the same or different conceptualization of language.

Solution: words are usually identified as ideas or concepts. For example, "law" is a word and at the same time an abstract concept in that it is a group of letters and sounds that signifies (i.e. the signifier(الدالّ/الإشارة)) a concept in language (i.e. the signified (المدلول عليه/الفكرة). These words have been already conceptualized in language and have thus become arbitrary basic concepts from which new concepts and conceptualizations are generated, derived or invented on the basis of social, linguistic, ideological, cultural, political, individual and religious factors. This means that conceptualization is not universal, but local/cultural. However, many concepts and conceptualizations can meet universally, others might cross swords with other languages and cultures. More likely, the majority of legal concepts and conceptualizations are universal. Yet, local and cultural conceptualizations are lurking in any language and culture (see examples below). 
Here is a detailed simplified example of how words are conceptualized culturally to become a part of our prior knowledge and experience of life, and how they breed new concepts and conceptualizations in a cognitive stylistic process and knowledge (see also Ghazala, 2016: 31-2):

$$
\text { (أقم الصلاة) (call for congregational prayer) }
$$

Firstly, to read this example, prior knowledge of Arabic is required. Readers who are not familiar with Arabic are also invited to explore the following account of the cognitive process of understanding and interpreting the concept of starting a congregational prayer. To understand this statement, the reader has to be equipped with knowledge of Islam according to which 'prayer' (Salat) is ordained five times a day at a specific time. Furthermore, he/she has to know beforehand that there are two ways of praying: alone (usually at home) and congregationally (usually at the mosque, starting from two people on). He/she also must already have a good idea about MOSQUE and how congregational prayers are held: a leader (or Imam) standing in the middle in front of worshipers, who line up right behind him in shoulder-to-shoulder rows and do what he does right after him concerning the start, units (rak'aas) and end of the prayer. As to the notion of MOSQUE, it should be a part of the stored knowledge of the reader: a large hall, usually rectangular, wellcarpeted, well-lit, clean, tidy, quiet, with a pulpit and a prayer niche (or Mihrab) in the middle of the inside front for the Imam, and usually with a high minaret constructed in the outside middle or on one of the outside corners of the mosque.

Now there might be variations on this basic knowledge of the notion of the MOSQUE. For example, some mosques are two floors, one (usually downstairs) for men, another (usually upstairs) for women. A number of mosques have two or more minarets which may vary in height. Usually mosques are air-conditioned and have loudspeakers. However, these facilities may not be available in some mosques. Wall decorations, wall-hanged and/or wall-carved verses from the Holy Koran (the Holy Book for Muslims) are different, sometimes sharply, from one mosque to another. Several mosques have shops attached to them, but the case may not be so for many others.

Yet, there can be a quite unusual cognitive experience of the notion of MOSQUE. I remember having had such an experience some years ago in 1986 when I was preparing my $\mathrm{PhD}$ Thesis in Stylistics at the University of Nottingham, UK, with a then newly constructed mosque at the University. There was a fridge inside the mosque, a help-yourself fridge crammed with chocolate bars and soft drinks available to worshipers, charged, or free of charge! 
A unique experience with the notion of MOSQUE is now available for everybody to watch on TV worldwide; that is, the live pictures of the Holy Mosque (i.e. Al-Haram Mosque) at Makkah AlMukarrammah of Saudi Arabia. It offers an exquisite cognitive experience of a completely different mosque, especially with respect to architecture, inside and outside shape, mixed lines of male and female worshipers praying, circumambulating around the Holy House of God, Kaaba, and galloping between the two Mounts of Safa and Marwah (i.e. Sa'i) (especially at the times of Hajj and Omrah, or mini-Hajj) and lining of worshippers in circular rows around the House of God, Kaaba, the prayer direction for all Muslims all over the world, which is in the centre of the Holy Mosque.

Thus, there are many concepts, conceptualizations and newly conceptualized concepts that have been formed, constructed, construed or invented on the way over time and new developments of life and the world. However, although all of them are interrelated, they have become concepts and conceptualizations of their own understood and used as such. A similar process can be applied to words and concepts and generating new concepts of other fields of knowledge and types of language including legal language.

Problem 2: an embarrassing situation can be come across by unheeded legal translators who might have no clear idea about differences in conceptualization of some words or concepts in the target language such as incriminating/non-incriminating some acts like adultery, wine drinking, polygamy, etc. Therefore, they translate SL terms literally or wrongly without attending to the sharply different conceptualization of their counterparts in the TL culture.

Solution: cognitive conceptualization of terminology is not necessarily the same in both languages involved, as is the case here with English and Arabic. Therefore, legal translators should be aware of that to avoid committing foolish mistakes by adopting the SL cultural concepts that are at odds with our conceptualization of these concepts. Adultery is a crime in our law and religion of Islam, whereas it is not in English law and religion; drinking wine is a daily practice of the English people and, hence, nothing is illegal about it. However, in Arabic law and religious and social culture, wine drinking is illegal and religiously forbidden with supposedly strict punishment. By analogy, polygamy is a crime in English and American laws, but getting married to more than one woman - up to for - at the same time is perfectly legal and religious. A father who takes his son's money is not a thief, whereas in English law he is. 
At translating these and other terms and words that are conceptualized differently in the TL, the translator should take that into account by translating its implied meaning, or rendering it literally followed by an illustrative comment, or a footnote if long. Take, for example, "polygamy/bigamy': it is translated heedlessly into (تعدد الزوجات) in Arabic, but its conceptual meaning is جعريمة تعدد) الزوجات والأزواج), which makes a big difference of conceptualization of legal meaning. The same applies to "polygyny" which has to be translated not into جريمة تعدد ) (تعدد الزوجات) but rather into (الزوجات). According the Free Legal Dictionary online, the three terms, polygamy, bigamy and polygyny, are described each as a crime (جريمة), felony (جناية) and offense (جرم) in American and English laws. The American Model Penal Code section 230.1, for example, provides that a person is guilty of the third-degree felony of polygamy if he or she marries or cohabits with more than one spouse at a time in purported exercise of the right of plural marriage. The crime is punishable either by a fine, imprisonment, or both, according to the law of the individual state and the circumstances of the offense. The crime of polygamy is deemed to continue until all cohabilitation with and claim of marriage to more than one spouse terminate. ... The law in every state prohibits a man or a woman from being married to more than one living person at a time. The crime of having more than one current spouse is called either bigamy (having two spouses) is a subset of the crime of polygamy (having more than one spouse). (see https://legaldictionary.thefreedictionary.com/Polygamy)

For all these reasons, the English terms express concepts and conceptualizations that are at odds with the TL counterparts which have to be precisely translated in accordance with the TL (i.e. national or cultural) legal conceptualizations of the concepts of the original. This means that the TL laws are not subdued to the SL laws in translation.

Problem 3: is legal terminology all in all culturally conceptualized? If so, the problems of translating it into Arabic will be daunting indeed, not to say impossible at least for some translators.

Solution: the answer is definite 'No!' Linguistically speaking, legal language is mainly universal, partly cultural. This is a fact about language, any language. In other words, languages are culturally (or locally / nationally) conceptualized only. Apart from the so-called international laws of international organizations like those of the United nations, judicial systems are cultural in the sense that each system is local and national, based on, designed for, and aimed at its local/national community. It cannot be applied as such in another country to a different community. 
For example, the British law cannot be applied in, say, Saudi Arabia, to the Saudi Community due to many differences of conceptualization including different cultural conceptualizations of all types: religious, social, political and linguistic. However, in the translation of legal English Language, we translate language in the conceptual context of the British judicial system, and not exactly in the British judicial system's conceptualization, as some may insist (i.e. we translate a judicial system into another judicial system). This is a purely theoretized over-statement. We translate the language that carries the meanings, concepts and implications of the British system into Arabic, with both translators and readers bearing in mind that it is in a British system context, not Arabic context.

Take for example the phrase "letter of advocation", which is a part of the Scottish law. We translate it into Arabic as (أمر قبول الدعوى الاستئنافية), preceded, or followed by the classifier, في القانون) (الأسكتلندي. By doing so, we give the clear meaning of the phrase in its locally conceptualized Scottish context. Nothing else is required from the translator other than translating the meaning of the phrase accurately and properly in its particular conceptual context, be it cultural or not. The fact about translating legal language is that it is mainly universal and, hence, pose the normal problems of translating appropriately and accurately into the target language. The remaining smaller part is culturally and locally conceptualized, which has to be translated with careful attendance to the cognitively cultural factor and how to render its conceptualized meaning into Arabic-conceptualized sense, using translation procedures like transference, paraphrase, classifier, naturalization, cultural equivalent, and so on.

On the other hand, cross-culturally conceptualized legal systems are frequent these days as countries borrow laws from one another for some specific reasons. One of these reasons is colonization of Arab countries which were colonized by France (like Syria, Lebanon, Algeria, Morocco and Tunisia) and, consequently, adopted many things from the French law; and countries that were occupied by the British, were influenced by the British law, and so on. In sum, Whatever this culturally conceptualized factor may be, it is no doubt TRANSLATABLE in some way, whether into Arabic or any other target language. Nothing is untranslatable; everything is translatable! No doubt, translating conceptualizations from one language into another is not insuperable. 


\section{Conclusions and Findings}

Several conclusions can be drawn from this research paper. One is that cognitive stylistic conceptualization of language in translation is a fact that we can make use of in legal translation to help us suggest further solutions to some problems of translating legal language. Another conclusion is that we cannot turn a blind eye to new findings of other disciplines like cognitive stylistics and apply them to legal translation, as translation is an interdisciplinary field of knowledge. A third conclusion is that conceptualization is not quite different from functionalization of legal translation for both approaches are TL-oriented and target readershipcentered, searching for a locally/nationally conceptualized equivalent of the meaning of an unfindable, or different SL term/meaning. A fourth and final conclusion and finding is that by cognitive conceptualization of legal translation, translators can touch upon more pathways of solutions to the problems of translating legal language, especially those concepts, meanings and implications that are either clashing, different or, generally. unfindable in the TL.

\section{References}

Alcaraz, E. and Hughes B. (2002). Legal Translation Explained. St. Jerome Publishing. (Published 2014 by Routledge).

Bajcic, Martina (2011). Conceptualization of legal terms in different fields of law: the need for a transparent terminological approach.Research in Language, 2011, vol. 9.1 • DOI 10.2478/v10015-011-0001-5 (pp.82-93).

Boase-Beier, J. (2006) Stylistic Approaches to Translation. St. Jerome Publishing: Manchester, UK \& Kinderhook, USA).

Boase-Beier, J. (2004a). 'Saying What Someone Else Meant: Style Relevance and Translation'. International Journal of Applied Linguistics, 14(2):276-287.

Cao, D. (2007). Translating Law. Multilingual Matters Ltd. Clevedon, Buffalo and Toronto. Cao, D. (2010). Handbook of Translation Studies. John Benjamins.

Carter, R. (1987). A question of interpretation: an overview of some recent developments in stylistics. In D'haen, Theo (ed.) (1986). Linguistic and the Study of Literature. Rodopi.

Crystal. D. (1987). The Cambridge Encyclopedia of Language, Cambridge University Press: Cambridge.

Fowler, R. (1977). Linguistics and the Novel. Methuen: London. 
Ghazala, H. (2011). Cognitive Stylistics and the Translator. Sayyab Books: London.

Ghazala, H. (2015). Translating Culture: A Textbook, Jedda, Saudi Arabia: Konooz Al-Marifa. Ghazala, H. (2018). The Cognitive Stylistic Translator. AWEJ for Translation \& Literary Studies, Vol.2, No. 1, pp. 4-25

Ghazala, H. (2020). The First Arabic Encyclopedia of Translation (الموسوعة العربية الأولى للترجمة) (in Arabic), Jedda, Saudi Arabia: Konooz Al-Marifa.

Ghazala, H. (2022) (forthcoming). Proximity Principle in Legal Translation.

Gutt, E. (2000). Translation and Relevance, $2^{\text {nd }}$ edn. St. Jerome: Manchester. https://legal-dictionary.thefreedictionary.com/Polygamy)

Jakobson, R. (1960) 'Closing Statement: Linguistics and Poetics', in Sebeok, T.A. (ed.) Style in Language, Cambridge: The MIT Press, 350-93.

Leech, G. and Short, M. (1981). Style in Fiction: A linguistic Introduction to English Fictional Prose. London and New York: Longman).

Malmkjaer, K. (2005). Translation and linguistics. Perspectives-studies in Translatology. 13(1):5-20.

Nida, E. (1964). Towards a Science of Translation. Leiden, E.J. Brill.

Nida, E. and Taber, C. (1969). The Theory and Practice of Translation. Leiden, E.J. Brill.

Nida, E. (1982/2001). Signs, Sense and Translation. Pretoria, University of Pretoria.

Nord, C. (1997). Translating as a Purposeful Activity: Functionalist Approaches Explained.

Manchester: St. Jerome.

Piecychna, B. (2013). Legal translation competence in the light of translational hermeneutics. Studies in Logic, Grammar and Rhetoric. 34 (1): 141-159.

Šarčević, S. (2000). 'Legal Translation and Translation Theory: A Receiver-oriented Approach', in La Traduction juridique: Histoire, theorie(s) et pratique, Geneve, Universite de Geneve, Ecole de Traduction et d'Interpretation /ASTTI, 329-347.

Semino, D. (2007). 'Translation and Society: The Emergence of a Conceptual Relationship', in St-Pierre, P. and Kar, P.(eds), In Translation - Reflections, Refractions, Transformations, (John Benjamins Publishing Company, Amsterdam / Philadelphia), pp. 13-26.

Stolze, R. (2013). The Legal Translator's Approach to Texts. Humanities, 2, 56-71.

Traugott, E. and Pratt, M. (1980). Linguistics for Students of Literature. Harcourt Brace Jovanovich Inc. 
Academic Journal of Research and Scientific Publishing | Vol 3 | Issue 33

Publication Date: 5-1-2022

Tyulenev, S. (2014). Translation and Sociology : An Introduction. Routledge, Taylor \& Francis: London and New York.

Whorf, B.L. (1956). Language, Thought and Reality, (ed.) J.B. Carroll.Cambridge, Mass: MIT Press.

Copyright (C) 2022 Dr. Hasan Said Ghazala, AJRSP. This is an Open-Access Article Distributed under the Terms of the Creative Commons Attribution License (CC BY NC)

Doi: https://doi.org/10.52132/Ajrsp.e.2022.33.4 